\title{
Who Benefits from Higher Education? An American Perspective
}

\section{Jamie P. Merisotis}

Jamie P. Merisotis is president of the Institute for Higher Education Policy. Address: 1320 19th St., NW, Washington DC 20036. Fax: 202/8619307.

A round the globe, higher education is in the midst of its greatest transformation since the end of World War II. Changes brought about by a variety of forces-advances in technology as a teaching and learning tool; the advent of new, usually for-profit postsecondary education providers; and changing student demographics, to name but a few-represent the cusp of a new era in higher education.

One recurring question seems to persist: why should a society invest in higher education? The American experience with higher education is instructive-particularly the goal of promoting greater access to college through low tuition and student financial assistance. Historically, the United States showed significant public support for, and understanding of, the social and economic benefits of attending college. Today, most discussions about the value of higher education are not about the broad range of benefits that it provides, but rather about the private economic benefits that result from going to college, such as higher salaries and better jobs.

\section{Research on the public and private benefits of going to college has not been widely analyzed.}

In some ways, the focus on the private economic benefits of education is understandable. After all, placing a dollar value on the returns to education puts a "personal" stamp on its importance and makes the often arcane talk about policies and programs more concrete for the public and for policymakers.

But what has been lost in this dialogue about higher education is a balanced view of the total array of benefits of the college experience. This more complete picture, which acknowledges the real private economic benefits of higher education but also emphasizes its social and democratic purposes, can provide policymakers and the public with a clear framework for understanding how investment in higher education benefits individuals and society. This enhanced dialogue is essential to maintain investment in higher education even as it is being transformed by technology, changing student populations, and a host of other factors.

Research on the public and private benefits of going to college exists in various reports and studies. However, many of these benefits have not been widely analyzed, and only a handful-especially those that have private economic effects-have been regularly discussed in public policy settings.

\section{Public Economic Benefits}

Public economic benefits are those benefits that have broad economic, fiscal, or labor market effects. In general, these benefits result in the overall improvement of the national economy, or major segments of the economy, as a result of citizens' participation in higher education. Some of the public economic benefits of higher education include:

- increased tax revenues-individuals with higher levels of education generally contribute more to the tax base as a result of their higher earnings;

- greater productivity-though American productivity has increased only modestly in the last two decades, nearly all of that increase has been attributed to the overall increased education level of the workforce;

- increased consumption-studies indicate that the overall growth in consumption in the last four decades is associated with the increasing education levels of society, even after controlling for income;

- increased workforce flexibility_higher education contributes to workforce flexibility by educating individuals in generalizable skills-critical thinking, writing, and interpersonal communication, each essential for economic competitiveness; and

- decreased reliance on government financial support-those who have attended college participate in government assistance programs at substantially lower rates than do high school graduates or those who have not graduated from high school.

\section{Private Economic Benefits}

This is the most commonly discussed category of higher education benefits. Private economic benefits are those benefits that have economic, fiscal, or labor market effects on the individuals who have attended postsecondary education. Examples include:

- higher salaries and benefits-in both lifetime and average annual income terms, individuals earn more as a result of their higher levels of education;

- employment-individuals who have gone to col- 
lege are employed at higher rates and with greater consistency;

- higher savings levels-surveys indicate that those with a bachelor's degree or more have greater interest-earning assets, home equity, and other financial assets;

- improved working conditions-people who have attended college tend to work more in white-collar jobs, in office buildings or other facilities with air conditioning and heating, and with conveniences (ranging from computers, to on-site child care, to consistent work hours) that improve the quality of their lives; and

- personal/professional mobility-research indicates that the ability to change jobs, or to relocate, is correlated with educational attainment.

\section{Public Social Benefits}

Public social benefits are benefits that accrue to groups of people, or to society broadly, that are not directly related to economic, fiscal, or labor market effects. Examples of such benefits include:

- reduced crime rates-incarceration rates indicate there are far fewer prisoners with at least some college education compared to those with a high school degree or less;

- increased charitable giving/community serviceseveral recent studies have found that a majority of those who have attended college perform volunteer work, and that financial contributions to charities were correlated with education levels;

- increased quality of civic life-significantly higher percentages of college-educated Americans vote in national elections;

- social cohesion/appreciation of diversity-research indicates that those with more than a high school education have significantly more trust in social institutions and participate in civic and community groups at much higher rates than others; and

- improved ability to adapt to and use technologycollege-educated individuals contribute more to research and development of products and services that enhance the quality of others' lives, and promote the diffusion of technology to benefit others.

\section{Private Social Benefits}

Private social benefits are benefits that accrue to individuals or groups that are not directly related to economic, fiscal, or labor market effects. Examples of these benefits include:

- improved health/life expectancy-surveys indicate that those with a college education exercise or play sports regularly at higher rates than do non-college-educated participants, and have longer life expectancies;

- improved quality of life for offspring-children whose parents have attended college appear to have a considerably better quality of life, are more likely to graduate from high school and continue on to college, are more likely to have higher cognitive development, and (in the case of daughters of college-educated mothers) are considerably less likely to become unmarried teen parents;

- better consumer decision making-individuals with higher levels of education have increased capacity to make informed, efficient decisions as consumers;

- increased personal status-having a college education has long been associated with increased personal status, as indicated by having a more prestigious job or being seen as a "leader" within a family, for example; and

- more hobbies, leisure activities-college-educated individuals go camping or hiking more frequently, and read literature at significantly higher rates than do high school graduates or those with less than a high school degree.

The preceding catalogue offers a window into the diverse benefits that can be associated with going to college. This typology indicates that a broad range of benefits, both public and private, economic and social, are related to the investment in higher education. Ultimately, responsibility for collecting and disseminating information about higher education's benefits is a shared one, involving colleges and universities, research organizations, the media, and governments. Working together, these entities can bridge the chasm in public and policymaker understanding about the outcomes of higher education, and lead to more rational, and long-term consideration of government and societal investment in postsecondary learning.

\section{Higher Education on the WWW}

Have you missed or lost an issue of the International Higher Education newsletter? Current and back issues, as well as news of the Center and up-to-date on-line resources and links related to comparative and international higher education are available on the World Wide Web. For more information visit the Center's website, located at:

\section{http://www.bc.edu/bc_org/avp/soe/cihe/}

